\title{
Abordagem da Antroposofia na Pediatria
}

Approach of Anthroposophy in Pediatrics

Enfoque de la Antroposofía en la Pediatría

Ricardo Ghelman ${ }^{1}$

\section{Resumo}

A Antroposofia aplicada à Saúde e a Medicina Antroposófica foram incorporadas à Política Nacional de Práticas Integrativas e Complementares do Ministério da Saúde em 2006 desde sua origem e correspondem a um modelo multimodal e multiprofissional europeu de cuidado integral à saúde infantil em baixa, média e alta complexidade, que vem se desenvolvendo amplamente no Brasil há mais de cinco décadas. Destacam-se como grandes áreas de contribuição internacional e nacional na saúde infantil - imunologia, infectologia, alergia, nutrição, medicina escolar e oncologia pediátrica. As evidências mostram que o emprego da Antroposofia como modelo complementar integrativo apresentam ótimo nível de segurança. Uma grande área em particular que a Medicina Antroposófica tem a colaborar na pediatria é na redução do emprego abusivo de antibióticos, anti-inflamatórios não-hormonais e hormonais em infeções respiratórias agudas e alergias respiratórias com boa taxa de resolução e segurança, podendo contribuir para a redução da taxa crescente de resistência antimicrobiana. Uma outra área muito promissora é a aplicação de técnicas de enfermagem denominadas terapias externas antroposóficas com baixo custo e boa resolutividade que podem ser expandidas na atenção primária, assim como nos outros níveis de complexidade.

Descritores: Pediatria; Antroposofia; Hipersensibilidade; Alergia e Imunologia; Saúde da Criança.

\begin{abstract}
Anthroposophy applied to Health and Anthroposophic Medicine were incorporated into the National Policy on Integrative and Complementary Practices of the Ministry of Health in 2006 from its origin and correspond to a multimodal and multiprofessional European model of comprehensive care for children's health in low, medium and high complexity, which has been developing widely in Brazil for more than five decades. They stand out as major areas of international and national contribution in children's health - immunology, infectology, allergy, nutrition, school medicine and pediatric oncology. The evidence shows that the use of Anthroposophy as an integrative complementary model presents an excellent level of safety. A large area in particular that Anthroposophic Medicine has to collaborate in pediatrics is in reducing the abusive use of antibiotics, non-hormonal and hormonal anti-inflammatories in acute respiratory infections and respiratory allergies with good resolution and safety, and may contribute to the reduction of the increasing rate of antimicrobial resistance. Another very promising area is the application of nursing techniques called anthroposophic external therapies with low cost and good resolution that can be expanded in primary care as well as in other levels of complexity.
\end{abstract}

\footnotetext{
${ }^{1}$ Doutor em Medicina (Área de Concentração: Toxicologia reprodutiva) pela Universidade Federal do São Paulo. Pós doutor pelo Programa de Neurociências do Departamento de Neurologia e Neurocirurgia da Universidade Federal do São Paulo/Escola Paulista de Medicina. Coordenador Científico da Unidade de Pediatria Integrativa e Professor Colaborador do Instituto da Criança do Hospital das Clínicas da Faculdade de Medicina da Universidade de São Paulo. Setor de Oncologia e Hematologia Infantil - Instituto de Tratamento do Câncer Infantil. Vice-presidente do Departamento de Genética da Sociedade de Pediatria de São Paulo (SPSP). Rua Galeno de Almeida, 148, São Paulo, SP - CEP 05410-030. E- mail: ric.ghelman@gmail.com
} 
Key-words: Pediatrics; Anthroposophy; Hypersensitivity; Allergy and Immunology; Child Health.

\section{Resumen}

Antroposofía aplicada a la salud y la medicina antroposófica fueron incorporados en la Política Nacional de Prácticas Complementaria y Integrativa del Ministerio de Salud en 2006 desde su origen y corresponden a un modelo multimodal y multidisciplinario europea de la atención integral a la salud del niño en baja, media y alta complejidad que se ha desarrollado ampliamente en Brasil por más de cinco décadas. Se destacan como las principales áreas de contribución internacional y nacional para la salud del niño - inmunología, enfermedades infecciosas, alergias, nutrición, medicina escolar y oncología pediátrica. La evidencia demuestra que el uso de la antroposofía como un modelo integrador complementaria tienen un nivel óptimo de seguridade. Un área en particular que medicina antroposófica tiene que contribuir a la reducción en pediatría es el uso incorrecto de los antibióticos, no esteroideos y los fármacos anti-inflamatorios esteroides en las infecciones respiratorias agudas y las alergias respiratórias con buena tasa de la seguridad y resolución, pueden contribuir a la reducción el aumento de la tasa de la resistencia antimicrobiana. Otra área muy prometedora es la aplicación de las denominadas técnicas de enfermería terapias externas antroposóficas con bajo costo y buena resolución de que se pueden ampliar en la atención primaria, así como en otros niveles de complejidad.

Palabras-claves: Pediatría; Antroposofía; Hipersensibilidad; Alergia e Inmunología; Salud del Niño.

\section{Introdução}

Desde a década de 90 do século XX a integração dos modelos terapêuticos tradicionais antigos (MT), das medicinas alternativas e complementares contemporâneas (MAC) com a medicina convencional (MC), todos embasados em evidências, constituiu um movimento mundial denominado medicina integrativa (MI) - que possui como premissas a ideia do cuidado integral à saúde, o cuidado centrado no paciente contemplando a empatia clínica, a promoção da saúde individualizada, a humanização das relações inter-profissionais, a construção de evidências científicas, mudanças na educação em saúde e busca de uma boa relação custo-efetividade. ${ }^{1-5}$

$\mathrm{Na}$ área da saúde infantil se desenvolveu o conceito de pediatria integrativa. Uma das características importantes da abordagem integrativa em pediatria é seu alto índice de segurança. Em estudo transversal suíço realizado em Zurich em 2010 em um centro de emergência pediátrica terciário aplicando 1143 questionários, as áreas complementares mais empregadas foram homeopatia (77\% dos usuários de MAC), fitoterapia (64\%), medicina antroposófica (24\%), medicina tradicional chinesa (13\%), medicina tradicional ayurvédica $(5 \%)$ e outras abordagens em $34 \%$. Os entrevistados descreveram que os custos diretos para o paciente de ambos os tipos de medicamentos complementares ou convencionais foram comparáveis. Noventa e três por cento (93\%) dos entrevistados não experimentaram efeitos colaterais com o uso de MAC, enquanto apenas $52 \%$ dos entrevistados afirmaram o mesmo sobre as terapias convencionais. Os efeitos 
ISSN 2179-6750

colaterais observados pelo uso de MAC foram mais fracos do que os de CM. ${ }^{6}$

As estratégias do Programa TM/CAM (Traditional Medicine / Complementary and Alternative Medicine) da Organização Mundial da Saúde (OMS) para o período 2014-2023, incluem a construção do conhecimento específico da área, o fortalecimento da qualidade na assistência, a garantia da segurança e efetividade da terapêutica além da cobertura dos serviços de medicina complementar nos serviços de saúde. ${ }^{7}$

Em 2006, seguindo esta tendência mundial, foi criada no Brasil no âmbito do Departamento de Atenção Básica do Ministério da Saúde (DAB/MS), a Política Nacional de Práticas Integrativas e Complementares (PNPIC), que incluiu inicialmente três sistemas médicos complexos ou racionalidades médicas: medicina tradicional chinesa, homeopatia e medicina antroposófica, e em 2017 incorporou a medicina ayurvédica. Cada uma destas quatro racionalidades médicas é formada por um conjunto de práticas e conhecimentos bem organizados e estruturados. Dentro do alcance das Práticas Integrativas e Complementares em Saúde (PICS), podemos distinguir sistemas médicos complexos ocidentais - como a medicina antroposófica e a homeopatia - e orientais - como a medicina tradicional chinesa e a medicina ayurvédica. Estão incluídos também uma série de recursos terapêuticos como, por exemplo, fitoterapia, termalismo/crenoterapia, arte terapia, musicoterapia, reiki e outras terapias corporais. ${ }^{8-10}$

\section{Métodos}

O presente estudo é descritivo com abordagem qualitativa da literatura científica que relata as evidências científicas atribuídas a Antroposofia na área de saúde infantil. O levantamento bibliográfico foi realizado utilizando bases de dados online, como Scientific Eletronic Library Onlin e (SciELO) e a Medical Publication (PubMed).

\section{Resultados e discussão}

Um estudo inédito em 2013 avaliou o uso PICS em pacientes pediátricos na Europa. Especialistas em pediatria integrativa em 20 países forneceram informações sobre a integração destas práticas, representando $68 \%$ da população europeia. Homeopatia, acupuntura e medicina antroposófica foram nomeados com maior frequência. A pediatria integrativa é oferecida em práticas privadas em todos os 20 países (100\%), e em $80 \%$ deles descreveu alguma forma de formação específica para profissionais de saúde. Enquanto as PICS sejam oferecidas em ambulatórios que tratam adultos em $80 \%$ destes países, apenas $35 \%$ oferecem PICS em ambulatórios pediátricos. Embora existem áreas de internação hospitalares dedicadas às PICS em 
ISSN 2179-6750

65\% dos países para adultos, apenas na Alemanha e na Holanda encontramos PICS em atenção secundária e terciária para crianças. A frequência de grupos de pesquisa em PICS esteve presente em $65 \%$ dos 20 países, e grupos focados em pesquisa com antroposofía em 50\%. A conclusão foi de que todas as crianças na Europa tiveram acesso ao tratamento das praticas integrativas, principalmente nos ambientes privados, enquanto as clínicas ambulatoriais e os serviços de internação para crianças são mais raros. ${ }^{11}$

Tais práticas com seus recursos terapêuticos conseguem reduzir significantemente o uso de antibióticos e anti-inflamatórios, empregados de forma abusiva na prática clínica pediátrica. Estas são premissas da OMS, que recomenda aos médicos uso criterioso de tais medicamentos, devido ao seu grande potencial de efeitos adversos à saúde. Infecções respiratórias agudas e otite média (IVAS) são freqüentes entre crianças e são comumente tratados com antibióticos. Em ensaios randomizados, os antibióticos têm apenas efeitos pequenos ou insignificantes a curto prazo sobre as IVAS, tais como faringite, bronquite, laringite e resfriado comum, comparáveis ao seu potencial efeito colateral. Além disso, o uso de antibióticos aumenta a resistência antimicrobiana, pode ser um fator de risco para a asma pediátrica, eczema atópico e doença infamatória intestinal crônica. ${ }^{12-26}$

A Comissão Europeia propôs recentemente um plano de ação contra as crescentes ameaças decorrentes da resistência antimicrobiana, que é estimada em 25.000 mortes humanas ao ano, bem como custos adicionais de saúde e perdas de produtividade de pelo menos 1,5 mil milhões de euros por ano. As estratégias para reduzir o uso de antibióticos incluem intervenções educacionais para médicos e pacientes, testes rápidos de antígenos para identificar doenças virais, adiamento intencional na prescrição de antibióticos e neste contexto o uso da medicina antroposófica pode contribuir neste esforço da redução da antibioticoterapia em casos bem indicados. ${ }^{27-30}$

Medicina antroposófica e Antroposofia aplicada à saúde

A medicina antroposófica teve suas origens no início do século XX na Europa, fruto do trabalho conjunto da médica holandesa Ita Wegman e do filósofo social austríaco Rudolf Steiner, criador da Antroposofia, filosofia que também originou a pedagogia Waldorf, a agricultura biodinâmica e a arquitetura antroposófica, dentre outras áreas do conhecimento humano. Chegou ao Brasil na década de 60 e foi reconhecida pelo Conselho Federal de Medicina (CFM) como prática médica na década de 90. Os medicamentos antroposóficos foram reconhecidos em 2007 pela Agência Nacional de Vigilância Sanitária (ANVISA), como categoria específica dentro dos medicamentos dinamizados, ao lado dos medicamentos homeopáticos e anti-homotóxicos, atualmente prescritos por mais de 30.000 médicos em 65 países de todo mundo, reunidos em 30 
ISSN 2179-6750

associações nacionais de médicos antroposóficos. ${ }^{9,31,32}$

A medicina antroposófica é praticada por médicos em ambulatórios públicos, consultórios privados, mas também em hospitais, departamentos em hospitais, centros de reabilitação, e outros centros de internação médica na Alemanha, Suíça, Suécia, Holanda, Estados Unidos e recentemente no Brasil. Na Alemanha, há doze hospitais antroposóficos, alguns dos quais são hospitais-escola. Em todos eles, se integra o tratamento convencional (como cirurgia, quimioterapia, radioterapia etc.) simultaneamente ao antroposófico, com o sentido do cuidado integral ao paciente. ${ }^{31}$

Em função da diversidade de profissionais de saúde vinculados a Antroposofia, nas áreas de medicina, odontologia, fisioterapia, farmácia, nutrição, psicologia, enfermagem, fonoaudiologia, educação terapêutica e outros, a coordenação do DAB/MS vinculado a PNPIC denominou este conjunto de Antroposofia Aplicada à Saúde e desenvolveu no Ambiente virtual de Aprendizagem do SUS (AVASUS) um curso de 80 horas denominado Módulo Introdutório em Práticas Integrativas e Complementares: Antroposofia Aplicada à Saúde. ${ }^{33}$

Sistema terapêutico na pediatria antroposófica e Antroposofia aplicada à saúde infantil

O sistema terapêutico da Antroposofia aplicada à Saúde, coerente com a visão tríplice do ser humano, deve abranger todas as dimensões da criança e adolescente e para isso se faz necessário um trabalho conjunto de uma equipe multiprofissional orientada pela Antroposofia. Ao nível da individualidade o aconselhador biográfico busca despertar a consciência dos pais e cuidadores quanto ao sentido da doença na biografia da família, a fim de fortalecer a resiliência e a reestruturação biográfica destes atores fundamentais na saúde da criança. $O$ aconselhamento biográfico corresponde a uma terapia breve, preferencialmente em grupo, de caráter higiênico e preventivo. ${ }^{34,35}$

No âmbito psíquico se desenvolve, principalmente, um trabalho com a psicologia infantil antroposófica e a terapia artística. A arte possui a característica de atingir diretamente a psique infantil, seja através do recurso da forma (desenho, modelagem com argila e escultura), da cor (pintura em aquarela), do som e do movimento (musicoterapia, cantoterapia e euritmia). Na área de interface saúde-educação a educaçãoo terapêutica se ocupa com crianças que necessitam de cuidados especiais, assim como o Extra-lesson atende crianças com dificuldade de aprendizagem e no desenvolvimento psico-neuro-motor.

O corpo, no sentido mais amplo, é cuidado através de medicamentos (farmácia antroposófica especialmente ligada aos laboratórios Weleda, Wala, Sirimim e Helixor), além de uma série de atividades terapêuticas como método padovan de reorganização neurofuncional da 
ISSN 2179-6750

fonoaudiologia, nutrição antroposófica, odontologia antroposófica, terapias externas, banhos terapêuticas e massagem rítimica típicas da enfermagem antroposófica, e quirofonética. As terapias externas antroposóficas correspondem a escalda-pés, enfaixamentos, compressas e emplastros à base de chás, óleos e pomadas fitoterápicas. Os banhos terapêuticos são realizados com a diluição de óleos de plantas medicinais na água da imersão. A massagem rítmica é inspirada na massagem sueca e, por intermédio de toques específicos como deslizamentos rítmicos superficiais, amassamento e malaxação, duplos círculos e lemniscatas, que atuam sobre as frações sólida, aquosa, gasosa e calórica do organismo permite seu reequilíbrio. ${ }^{36-44}$

A terapêutica medicamentosa é realizada exclusivamente por médicos e dentistas, que prescrevem de acordo com o diagnóstico individualizado, associando as três farmacopéias com boa segurança. As farmacopeias são a alopática (sintética, físico-química), empregada em apenas $40 \%$ dos medicamentos prescritos, fitoterápica (extrato com princípios ativos definidos, tintura mãe ou infusão) e dinamizados propriamente ditos seguindo as normas da farmacopeia antroposófica. Os medicamentos dinamizados antroposóficos injetáveis, geralmente de uso sub-cutâneo, são indicados nas seguintes situações:

- Princípio ativo inativado no trato digestivo: por exemplo Viscum album em oncologia e imunodepressão;

- Pacientes graves impossibilitados de medicação por via oral: por exemplo Arnica D20 em traumatismos cranianos com pacientes comatosos;

- Pré, per e pós-operatórios eletivos e de urgência;

- Pacientes com síndromes disabsortivas intestinais; e

- Necessidade de intensificar efeito do medicamento, por exemplo Aurum met prap D10/Ferrum sidereum D10 em casos de depressão leve e moderada. ${ }^{32,45,46}$

Embora o tratamento das crianças possua um domínio central da medicina antroposófica desde a sua criação, são necessárias revisões sistemáticas das terapias antroposóficas na atenção primária pediátrica. Um estudo conduzido por Jeschke et al. em 2011 descreveu o espectro de diagnósticos e terapias observadas em crianças tratadas na prática antroposófica diária. Trinta e oito médicos de atenção primária na Alemanha participaram deste estudo prospectivo, multicêntrico observacional sobre padrões de prescrição. Prescrições e diagnósticos foram relatados para cada paciente consecutivo. Em 2005, foram emitidas 57.893 prescrições para 18.440 crianças menores de 12 anos (48,1\% mulheres). No total, $50,3 \%$ das prescrições foram classificadas como remédios complementares apenas, 22,6\% como produtos farmacêuticos convencionais sozinhos e 27,1\% como uma combinação de ambos. Os remédios antroposóficos representaram $41,8 \%$ de todos os 238 
ISSN 2179-6750

medicamentos prescritos. A frequencia para receber um remédio antroposófico foi significativamente maior na primeira consulta. Os remédios antroposóficos foram prescritos mais freqüentemente na seguinte sequencia de indicações: para, infecções agudas do trato respiratório superior (IVAS), doenças respiratórias crônicas, distúrbios agudos da conjuntiva, sintomas digestivos e abdominais, pneumonia e sintomatologia geral. A probabilidade de ser prescrito um remédio antroposófico diminuiu com a idade do paciente e foi menor nos pacientes tratados por pediatra do que por médicos de família. Dos 2.475 procedimentos terapêuticos não-farmacológicos encaminhados (29\% antroposóficos), os mais freqüentes foram fisioterapia, fonoaudiología e outras terapias corporais. O presente estudo foi o primeiro a fornecer uma visão sistemática da prática médica antroposófica diária na atenção primária para crianças, demonstrando a abordagem integrativa. ${ }^{47}$

Talvez a terapêutica antroposófica não-farmacológica de origem mais brasileira e muito usada em pediatria seja o Metodo Padovan de Reorganização Neuro-funcional (RNF), uma abordagem terapêutica da fonoaudiologia que recapitula as fases do neuro-desenvolvimento infantil. São empregadas como estratégia para habilitar ou reabilitar o sistema neuro-muscular como um todo incluindo a fala, linguagem, atenção e controle motor grosseiro e fino. As indicações na área da linguagem são: distúrbios articulatórios em geral como trocas, omissões substituições de fonemas, afasias motoras e sensoriais, atraso de linguagem, gagueira e etc.; na área de aprendizagem: déficit de atenção e concentração, dislexia, discalculia e disgrafia; na área de motricidade oral: respiração bucal ou oral, deglutição atípica, disfagia (dificuldade para deglutir), maus hábitos orais e controle de esfíncter. Em estudo clínico em pacientes que tiveram como manifestação na vida adulta disfagia, como sintoma de síndrome pós poliomielite (SPP) após incidente de poliomielite na infância, a RNF foi capaz de reabilitar esta função com melhora referida dos sintomas. ${ }^{48,49}$

Teoria de desenvolvimento na pediatria antroposófica

No campo da saúde infantil, uma das grandes contribuições da Antroposofia é sua teoria de desenvolvimento humano em ciclos temporais ao longo da biografia. Estes ciclos podem ter variações individuais, no entanto norteiam a compreensão do profissional de saúde quando atende um paciente com uma idade específica, criando um pano de fundo para a contextualização da história de saúde e doença e da queixa principal. A biografia humana, em seu percurso temporal, apresenta uma organização tríplice, uma vez que segundo a Antroposofia o ser humano possui uma constituição tríplice noo-psico-somática que precisaria de pelo menos 63 anos para completar seu ciclo de desenvolvimento. A noética (do grego nous: mente) é uma disciplina que estuda os fenômenos subjetivos da consciência, da mente e do espírito a partir do ponto de vista da ciência. 
ISSN 2179-6750

Como conceito filosófico em linhas gerais define a dimensão espiritual do homem.

Precisamos aproximadamente dos primeiros 21 anos para amadurecermos nosso corpo. Este período essencialmente somático, que corresponde a infância e adolescência poderia ser chamado de primeira fase. Dos 21 aos 42 anos amadurecemos nossa psique - segunda fase - e após os 42 anos desenvolvermos na terceira fase especialmente nossa dimensão noética, da individualidade ou Self, simultaneamente a redução da funcionalidade orgânica. Após os 63 anos entraríamos numa quarta fase, mais livre de padrões biográficos, como uma fase de colheita dos anos anteriores.

Cada um destes grandes ciclos pode ainda ser subdividido em três períodos de sete anos - os setenios - que correspondem a uma unidade de tempo do desenvolvimento humano. Portanto até os 63 anos existem 3 ciclos de 3 setenios, como seu ápice ao redor de 31 anos, que corresponde ao ápice de equilíbrio metabólico entre o anabolismo da infância e o catabolismo oxidativo do adulto. Enquanto o pediatra e o hebiatra acompanham a maior parte do desenvolvimento humano no sentido crânio-caudal até o término do processo de ossificação aos 28 anos, de forma especular, o clinico geral e o geriatra assistem um processo de retração da atividade orgânica dos pacientes no sentido caudo-cranial a partir dos 35 anos de idade, de forma que a menarca e a menopausa são espelhamentos no tempo em relação a 31 anos de idade, se observarmos que ambos ocorrem ao redor de 20 anos antes e após este pico biográfico de plateau metabólico quando por um curto período existe um equilíbrio entre anabolismo e catabolismo. ${ }^{34,35,50-52}$

A pediatria se ocupa especialmente com estes três primeiros setênios, ou seja, o período de 0 a 6/7 anos, o período de 6/7 a 12/14 anos e o período de 12/14 a 20/21 anos, que correspondem a fases tão distintas que poderíamos denominar de três infâncias, embora segundo a OMS o terceiro período da adolescência ocorre entre 10 e 20 anos de idade.

Considerando que a criança apresenta quatro dimensões pela visão antroposófica, ou seja, uma dimensão física-mineral, uma dimensão de vitalidade-vegetativa, uma dimensão psíquicaanimal e uma dimensão noética-humana, expressão de sua individualidade, ela vai necessitar de quatro partos, a cada sete anos aproximadamente, para que chegue a fase adulta ao redor de 21 anos. Estas quatro dimensões funcionam como campos morfogenéticos com características organizacionais e podem, portanto, serem denominadas organização física, organização vital, organização anímica e organização do eu, coordenando a morfologia e fisiologia óssea-mineral, dos fluidos, dos lipídeos/gases e da estrutura térmica, respectivamente. ${ }^{53,54}$

No primeiro parto na maternidade ou domiciliar, ela finaliza um período de organogênese durante o desenvolvimento embrionário e fetal e se separa fisicamente da mãe. Ao redor de sete anos ocorre o final do processo de mielinização cerebral, da produção de alvéolos pulmonares, a da 
ISSN 2179-6750

produção de adipócitos (hipertrofia), simultaneamente a troca dos dentes. É como se fosse um segundo parto que separa a primeira da segunda infância. Na criança até 6 a 7 anos o neurodesenvolvimento é tão surpreendente e altamente sensível a estímulos externos que existe o conceito de janela de plasticidade epigenética para esta fase. Enquanto na primeira infância nãomielinizada a criança vive em seu mundo de fantasia, com enorme força de vontade, adquire nos seus três primeiros anos, três habilidades que são características eminentemente humanas: o andar ereto, a fala complexa e o pensar auto reflexivo que permite que a criança se chame de Eu ao redor do segundo ano de vida. Pela sua importância estes três primeiros anos ontogenéticos do desenvolvimento infantil correspondem a milhões de anos filogenéticos, uma vez que as aquisições do andar ereto com liberação das mãos foram conquistadas pelo Homo erectus e pelo Homo habilis. Tanto as consciências reflexivas como a fala complexa refletem um grau maior de autoconsciência que só foram conquistadas pelo Homo sapiens.

Já na segunda infância mielinizada a criança vive um crescimento de sua inteligência cognitiva-racional com muitas perguntas e muita afetividade. Por volta de 10 a 14 anos, na puberdade, existe um novo parto, agora de cunho hormonal com grande mudança corporal e de comportamento, caracterizado pela dismorfia sexual do gênero masculino ou feminino, finalizando a segunda infância. A terceira infância que se inicia com a denominação de adolescência, sob o cuidado da hebiatria, vai lidar com uma enorme e nova expansão de consciência repleta de questionamentos, conjuntamente com a explosão da sexualidade que traz como um terceiro nascimento.

Enfim próximo aos 21 anos, terminada esta travessia em termos de maturidade, realmente nasce um adulto jovem a partir da maioridade como expressão de seu Self ou Eu em seu último parto. Do ponto de vista somático neste período se adquire maior equilíbrio, postura mais ereta, um olhar mais presente, melhor controle da homeotermia e mais imunocompetência. Expressões desta dimensão noética no fim da adolescência surgem novas capacidades como aumento da resiliência, enfrentamento, coerência, autoconsciência e alteridade, que em somatória elevam as forças salutogenéticas como um fator promotor de saúde, a despeito das adversidades ambientais. Embora os agentes infecciosos se mantenham no ambiente, a incidência de infecções agudas cai drasticamente a partir da segunda infância até quase desaparecer após os 21 anos.

Define-se resiliência como uma capacidade de enfrentar criativamente a vida, especialmente em situações de estresse. A resiliência envolve três inteligências: a inteligência comportamental relacionada à força de vontade e à ação no mundo -, a inteligência emocional e a inteligência cognitiva - que tem relação com o QI, Quociente de Inteligência. É preciso passar por toda infância 
ISSN 2179-6750

para desenvolver todas essas inteligências. A primeira inteligência, que tem a ver com a primeira infância dá capacidade de manuseio da vida: saber enfrentar situações e buscar ajuda. A inteligência emocional, ligada à segunda infância, dá significado e sentido às coisas. A terceira inteligência dá capacidade de compreender o mundo. São essas três inteligências que tornam as pessoas inteiramente resilientes segundo o sociólogo da saúde Aron Antonovsky. ${ }^{55-57}$

Sistemas morfo-funcionais na pediatria antroposófica

Uma importante concepção sistêmica antroposófica considera que a criança possui três sistemas morfo-funcionais psicossomáticos, que se interpenetram - o sistema neuro-sensorial (SNS) que se desenvolve mais na primeira infância, o sistema rítmico (SR) mais na segunda infância e o sistema metabólico-motor (SMM) mais na terceira infância, centrados na cabeça, tórax e abdome/membros, respectivamente. Eles se manifestam precocemente no desenvolvimento embrionário através do estabelecimento dos três folhetos - ectoderma, mesoderma e endoderma e continuam até os 21 anos criando este padrão crânio-caudal de crescimento e desenvolvimento.

O SNS, associado ao ectoderma, embora centrado na cabeça, estende sua atuação sobre todas as células, tecidos, sistemas e aparelhos relacionados à percepção e consciência, ou seja, até o tato periférico nas falanges. Este sistema se caracteriza pela disposição anatômica simétrica direitoesquerda e pela situação periférica dos ossos cranianos. Funcionalmente possui baixíssima vitalidade, manifesta na pouca capacidade de regeneração nervosa, que se acentua em situações de excesso de exigência da atividade nervosa, como na síndrome de privação de sono. O SNS está relacionado à consciência, sua função é potencializada no frio e está vinculado à musculatura estriada esquelética voluntária de disposição simétrica. A inervação somática, especifica para esta musculatura referida e para os órgãos sensoriais, tem vínculo direto com o SNS.

Na região do abdome e dos membros, o SMM, associado ao endoderma e ao mesoderma, possui seu centro de atuação que se estende por todas as atividades metabólicas não sensoriais até a nutrição neuronal por parte das células da glia. Morfologicamente cria formas assimétricas, órgãos impares (fígado, vesícula biliar, pâncreas, baço), formas espiraladas (intestino, mielina) e ossos de localização central (ossos longos dos membros). Funcionalmente apresenta capacidade regenerativa intensa e potencialização funcional no calor. Tanto a musculatura lisa, involuntária, se vincula a este sistema metabólico -motor, como a inervação visceral ou autônoma.

Entre os dois sistemas opostos, se manifesta o sistema de equilíbrio chamado de sistema rítmico (SR), associado ao mesoderma e ao endoderma. O SR se responsabiliza pela conciliação entre as atividades da percepção e as atividades da movimentação/excreção, no ritmo de contração e 
ISSN 2179-6750

expansão tão bem representada na atividade cardio-respiratória, centrada na caixa torácica e que se expande por todo território corporal. Até mesmo os ossos e músculos desta região resolveram o problema de integração. Morfologicamente os ossos da caixa torárica possuem uma apresentação entre a reta e a curva, o dentro e o fora, assim como a musculatura cardíaca representa uma incrível síntese das duas musculaturas em uma forma mista estriada-lisa no centro do sistema rítmico e o diafragma possui inervação somática e visceral, servindo de ponte entre o sistema nervoso somático consciente neurosensorial e o sistema nervoso visceral inconsciente metabólico. ${ }^{41,43,53,58}$

A pediatria se especializa neste primeiro ciclo de 21 anos de vida, quando o SMM se destaca com suas atividades anabólicas e calóricas. De forma quase oposta a Clínica Médica e a Geriatria se ocupam quando as atividades catabólicas e de consciência, típicas do SNS, predominam. No meio da vida, entre os 21 e os 42 anos de idade, existe um equilíbrio entre os dois sistemas através do SR, especialmente entre os 28 e os 35 anos de idade. Nesta fase acontece uma condição de saúde interna que só é abalada por acidentes, homicídios e infarto agudo do miocárdio por uma vida demasiada arrítmica, razão pela qual epidemiologicamente encontrarmos menos doenças nesta fase mediana da vida.

Com base nesta psicossomática antroposófica, consideramos o adoecimento orgânico como a manifestação da hiperatividade e/ou hipoatividade de um dos dois sistemas polares. O predomínio do sistema metabólico-motor termogênico gera as doenças inflamatórias agudas, típicas da infância, enquanto que o predomínio do sistema neurosensorial conduz ao desenvolvimento das doenças crônico degenerativas, de caráter inflamatório crônico e esclerótico, típico da segunda metade da vida.

No entanto este padrão inflamatório típico do adulto, vem acometendo cada vez mais as crianças na forma de processos inflamatórios crônicos como alergia e síndrome metabólica. ${ }^{53}$

Vejamos a seguir as grandes contribuições da Antroposofia aplicada a Saúde na Pediatria.

Imunologia e pediatria antroposófica

Em decorrência da função central do sistema imune de manutenção da identidade imunológica através da discriminação do Self e não-Self, a Antroposofia relaciona o sistema imune a nossa dimensão noética, e considera que o desenvolvimento da resiliência e a promoção da saúde dependem fundamentalmente da relação entre nossa individualidade e nosso corpo. Nas fronteiras de nosso corpo existe uma concentração de atividade imune que envolve o território cutâneomucoso, com toda rede linfática subjacente. Neste sentido o primeiro setenio corresponde a um período especial, pois o sistema imune tanto inato como adaptativo amadurecem com grande 243 
ISSN 2179-6750

desenvolvimento do tecido linfoide na construção de uma memória imunológica adequada. ${ }^{39}$

$\mathrm{Na}$ infância podemos encontrar uma imunodeficiência seja congênita ou adquirida permitindo a invasão destas fronteiras por agentes infecciosos virais, bacterianos, micobacterianos, fúngicos e até parasitários provenientes do ambiente. Por outro lado, podemos encontrar uma condição de produção de anticorpos contra o ambiente promovendo um processo inflamatório nas mesmas fronteiras, de tal forma que uma inflamação em pele ou mucosas pode ter como diagnóstico tanto uma infecção como alergia.

O sistema imune possui uma atividade sensorial que percebe o ambiente e uma atividade executiva que inflama com padrões variáveis. Na perspectiva antroposófica esta função sensorial corresponderia a região neurosensorial do sistema imune, enquanto a função inflamatória representa a região metabólica do sistema imune. Nas doenças inflamatórias agudas, de caráter infeccioso, a inflamação ocorre de forma violenta e rápida coordenado pelas citocinas dos linfócitos T helper tipo 1 (TH1) como IL-2, IL-3, IL-12, IFN- $\gamma$ e FNT- $\beta$, que induzem a febre a dor muscular. Nas inflamações crônicas e frias, o sistema imune assume o modo TH2 típico dos adultos, sem febre, envolvendo as citocinas típicas do padrão neurosensorial IL-4, IL-5, IL-6, IL-9, IL-10, IL-13. ${ }^{53}$

A alergia é uma doença de hipersensibilidade do sistema imune, que se manifesta nas regiões das fronteiras corporais cutâneo-mucosas, aonde a atividade sensorial fica hiperativa e como resposta alterada assume um padrão inflamatório crônico frio tipo Th2 com síntese aumentada de eosinófilos e anticorpos da classe IgE. Assim nas alergias, do ponto de vista antroposófico, o SNS está hipertrofiado, manifestando-se como em estado de alerta, de hiperatenção, muitas vezes associado a um sono mais leve ou insônia nas crianças acometidas e ao déficit de atenção. Existe, por consequência, a produção de um excesso de IgE contra o ambiente, sejam ácaros, poeira, pólen, alimentos, e que podem ser estimulados por variações de temperatura e forte carga emocional. Em contrapartida, nos indivíduos alérgicos o sistema metabólico motor está deficiente, provocando muitas vezes má digestão com flatulência, intolerância a alguns alimentos, constipação intestinal, extremidades frias e palidez cutânea. Esta fraqueza metabólica de crianças alérgicas promove uma dificuldade de manter adequadamente um equilíbrio térmico e de gerar febres.

Neste sentido, o médico e o nutricionista antroposófico dão enorme valor a função digestória do intestino e das secreções hepato-biliares-pancreáticas que devem ser estimuladas com temperos e medicamentos colagôgos adequados como da família botânica das Lamiaceae como orégano, manjericão, tomilho, alecrim, entre outros temperos termogênicos como canela e gengibre e por medicamentos antroposóficos específicos estimulantes do sistema hepato-biliar como Chelidonium majus, Gentiana lutea, Taraxacum off, Absinthium artemisia, Urtica urens e Pneumus boldus. Para 
ISSN 2179-6750

equilibrar as quatro organizações morfo-genéticas através de medicamentos antroposóficos podemos empregar na forma dinamizada em concentrações seguras, por exemplo, para a organização calórica do Eu - Apis mellifica, Aconitum napelus, Equinacea purpurea, Viscum album, Ferrum sidereum, Phosforus metalicum praeparatum, Aurum metallicum e Silicea; para a organização anímica-sensorial - Berberis vulgaris, Arsenicum album, Cydonia oblonga, Atropa belladona, Colocynthis, Cuprum metallicum, Magnesium phosphoricum, Mandragora, Nicotiana tabacum; para a organização hídrico-vital - Bryonia alba, Hydrastis canadensis, Argentum metallicum, Bryophyllum calycinum e Prunus spinosa. Em crianças imunodeprimidas a capacidade de manter a homeotermia está comprometida. Nas crianças alérgicas especialmente a organização anímica-sensorial está hiperativa. ${ }^{53,54}$

Nas crianças que são muito estimuladas do ponto de vista sensorial e cognitivo e, especialmente de forma precoce, como por uma alfabetização intensa antes dos 6 anos de idade, excesso de tempo sedentário em uso de tecnologia eletrônica, apresentam aumento da incidência e agravamento das alergias. Uma alimentação com consumo exagerado de doces e alimentos ácidos, azedos, gordurosos e industrializados com corantes artificiais, também podem potencialiazar a alergia. Por outro lado, um estilo de vida que privilegia o movimento, o contato rico com a natureza em ambientes abertos, uma alimentação mais orgânica, biodiversa e rica, restrição ao uso de tecnologia apresentam melhora da evolução do quadro alérgico. Uma atividade física vigorosa consegue simular de forma fisiológica os sinais flogísticos típicos do padrão infmamatório TH1 que está enfraquecido nestas crianças - rubor, edema, dor e calor. Esta simples orientação aos pais de que privilegiem nas crianças alérgicas a atividade física outdoor em detrimento de atividades sedentárias e intelectuais, pode gerar um impacto na modulação do sistema imune com melhora da sintomatologia alérgica e redução de crises. ${ }^{38,58}$

Se esse padrão neurosensorial atuar excessivamente no sistema rítmico de crianças alérgicas, surgem os sintomas da asma, especialmente o broncoespasmo. Tambem pode se desenvolver uma secreção eosinofílica que pode progredir até a mineralização com a formação de cristais de Charcot-Leyden. A substância destes cristais consiste em agulhas de ácidos graxos, octaédricas, provenientes das granulações de leucócitos eosinófilos destruídos. Em caso extremo, encontra-se até sais de cálcio. A visão de que esses processos partem do polo cefálico neurosensorial, também pode ser verificado na evolução natural da doença em casos extremos através das características morfológicas e funcionais do pulmão. No caso da cronificação sem adequado controle, a asma evolui para o enfisema pulmonar e a doença pulmonar obstrutiva crônica (DPOC). Estas características patológicas impregnam no tórax 
ISSN 2179-6750

um padrão cefálico com rigidez e forma mais esférica na caixa torácica, processo denominado de encefalização do tórax. ${ }^{40,41,43}$

O estudo IIPCOS-Antroposofia (International Integrative Primary Care Outcomes StudyAnthroposophy) foi conduzido em 1999-2000 nos serviços de atenção primária na Áustria, Alemanha, Holanda, Reino Unido e nos Estados Unidos avaliando o atendimento a crianças com IVAS. Neste estudo Hamre et al. (2005) avaliaram os tratamentos médicos de rotina. Dois grupos de pacientes foram comparados de acordo com o tratamento proposto pelos médicos: pacientes que atendiam terapia antroposófica (grupo A) e pacientes que receberam terapia convencional (grupo C). O estudo com desenho prospectivo, não randomizado, multicêntrico envolveu 1.016 pacientes (715 adultos e 301 crianças) concluiu que comparado com tratamento convencional, o tratamento antroposófico no primeiro atendimento em pacientes com sintomas respiratórios e otológicos agudos teve resolução mais favorável, menor índice de prescrição de antibióticos, menos reações adversas e maior satisfação de pacientes. ${ }^{59}$

Em 2014 um estudo observacional multicentrico que incluiu 529 crianças menores de 18 anos da Europa (Austria, Alemanha, Holanda e Reino Unido) e dos EUA, comparou a sub-populção de pacientes que escolheram consultar médicos antroposóficos (A) ou convencionais (C), sem diferenças demográficas nem de morbidade basal. A conclusão deste estudo prospectivo observacional em condições de rotina de cuidados primários mostrou um uso muito baixo de antibióticos e analgésicos/antipiréticos em crianças tratadas para IVAS por médicos A, em comparação com a prática em terapias convencionais (C). Durante o seguimento de 28 dias, os antibióticos foram prescritos para 5,5\% dos pacientes acompanhados por A e 25,6\% dos pacientes acompanhados por $\mathrm{C}(\mathrm{p} \leq 0,001)$. Em comparação com os pacientes do grupo $\mathrm{C}$, os pacientes do grupo A também apresentaram menor uso de analgésicos - 3\% versus $26 \%$, respectivamente -, resolução um pouco mais rápida dos sintomas e maior satisfação dos cuidadores. As reações adversas foram pouco frequentes $(2,3 \% \mathrm{em}$ ambos os grupos) e não graves. O tratamento antroposófico não implicou em nenhum problema de segurança e não foi associado a uma recuperação mais tardia. ${ }^{60}$

Uma das medicações mais utilizadas pela medicina antroposófica como imunoterapia é o Viscum album, fármaco com ação biologica complexa indicado por via parenteral geralmente via sub-cutânea em oncología e infectologia há quase 100 anos.

Em um estudo russo, noventa e duas crianças de 5 a 14 anos de idade que viviam em áreas expostas à contaminação radioativa de Chernobyl com infecções respiratórias baixas recorrentes (pneumonia de repetição) foram tratadas após a randomização com o Viscum álbum Mali ou Pini 
ISSN 2179-6750

(Iscador M ou P). A esquema terapeutico foi de duas injecções subcutâneas por semana durante 5 semanas com doses individuais de 0,001 mg a 1,0 mg. Ambas as preparações de Viscum foram eficazes na redução significativa de sintomas clínicos. Um ano após um único ciclo de tratamento, a freqüência de recidivas diminuiu em 78\% (Viscum M) e 73\% (Viscum P), respectivamente. Os efeitos imunomoduladores foram avaliados por investigação de subgrupos de linfócitos, atividade de células natural killer (NK), actividade fagocítica e oxidativa de leucócitos polimorfonucleares e atividade antiviral do soro antes e uma semana após o tratamento. A terapia com viscum resultou na normalização dos índices imunitários iniciais. ${ }^{61}$

Um outro medicamento usado amplamente em medicina antroposófica na conjuntivite inflamatória é o colírio a base do fitoterápico Euphrasia rostkoviana. Um estudo coorte prospectivo, aberto, com um braço, multicêntrico e multinacional buscou descrever a eficácia e tolerabilidade deste colírio. $\mathrm{O}$ estudo foi conduzido em unidades de saúde de 12 médicos gerais antroposóficos experientes e oftalmologistas na Alemanha e na Suíça. Foi prescrito colirio de Euphrasia na dose de uma gota oftálmicas 1-5 vezes por dia para pacientes com conjuntivite inflamatória. As variáveis clínicas de eficácia foram: eritema, edema, secreção, sensação de queimação da conjuntiva e/ou de corpo estranho. Todos os sintomas foram avaliados para o olho direito ou esquerdo separadamente, em dois exames de seguimento aos 7 e 14 dias. Uma recuperação completa foi observada em 53 pacientes, ou seja 81,5\%, e uma clara melhora em 11 pacientes $(17,0 \%)$. Um ligeiro agravamento só pôde ser determinado em 1 doente na segunda semana de tratamento (1,5\%). Não foram observados efeitos adversos graves durante todo o ensaio. A eficácia e a tolerabilidade foram avaliadas pelos pacientes e médicos como "bons" a "muito bons" em mais de 85\%. Neste estudo Euphrasia colirio oftálmico em uso em média de 3 vezes ao dia apresentou eficácia e segurança em várias condições conjuntivais segundo médicos de clínica geral e oftalmologistas. ${ }^{62}$

\section{Evidências em alergia}

Andriashvili et al. avaliaram em 2007 a eficiência do tratamento antroposófico da asma brônquica em crianças. Os autores conduziram um estudo com 92 pacientes de 3 a 15 anos com asma brônquica durante dois anos, comparando 60 crianças tratadas com remédios antroposóficos com 32 crianças tratadas pelo esquema clásico (grupo controle). Conclui-se que os remédios antroposóficos, tornaram a doença mais suave e com aumento do período de remissão entre as crises. Concluiram que os remédios antroposóficos como tratamento complementar tornaram o tratamento mais eficaz e permitiram reduzir e/ou substituir os remédios sintéticos. ${ }^{63}$ 
ISSN 2179-6750

Hamre et al. avaliaram em 2009 pacientes ambulatoriais iniciando tratamento antroposófico para asma em condições de rotina na Alemanha. Foram incluídos 90 pacientes (54 adultos, 36 crianças). As modalidades de tratamento antroposóficas utilizadas foram medicamentos (88\% dos doentes); terapia com euritmia (22\%); arteterapia (10\%); terapia de massagem rítmica (1\%). O número médio de sessões de euritmia / arte / massagem foi de 12, com duração média da terapia de 120 dias (84-184). Desde o início até o seguimento de 12 meses, todos os resultados melhoraram significativamente ( $p<0,001$ para todas as comparações). As melhorias foram redução na gravidade média da asma, da tosse, da dispnéia, dos sintomas induzidos por esforço, da frequência de ataques de asma, do despertar da asma, da pontuação geral dos questionários de vida no módulo de asma e KINDL. Todas as melhorias foram mantidas até o último seguimento após 24 meses. Como conclusão os pacientes com asma sob tratamento antroposófico apresentaram melhora a longo prazo dos sintomas e da qualidade de vida. ${ }^{64}$

Há quase duas décadas a literatura aponta para um estilo de vida antroposófico de crianças que frequentam escolas Waldorf interferindo na evolução da alergia infantil. As crianças que seguem um estilo de vida antroposófico usam antibióticos restritivamente, têm menos vacinas e sua dieta geralmente contém lactobacilos vivos, que podem afetar positivamente a microflora intestinal. Para estudar a prevalência de atopia em crianças de famílias antroposóficas e a influência de um estilo de vida antroposófico na prevalência de atopia, Alm et al. publicaram na revista Lancet em 1999 os resultados de um estudo transversal, compararam-se 295 crianças com idades entre 5 e 13 anos provenientes de duas escolas suecas antroposóficas (Waldorf) próximas a Estocolmo, com 380 crianças da mesma idade em duas escolas vizinhas em termos de história de doenças atópicas e infecciosas, uso de antibióticos e vacinas e variáveis sociais e ambientais. Testes cutâneos foram feitos para 13 alérgenos assim como foram realizadas analises de anticorpos IgE específicos para alérgenos. Nas escolas Waldorf, $52 \%$ das crianças tinham recebido antibióticos no passado, em comparação com $90 \%$ nas escolas de controle. As vacinaçõees foram semelhantes, exceto quanto a imunização combinada contra sarampo, caxumba e rubéola (vacina SCR), $18 \%$ nas crianças Waldorf e $93 \%$ das crianças do grupo controle. A prevalencia de sarampo entre o grupo Waldorf foi de $61 \%$. Os vegetais fermentados, contendo lactobacilos vivos, foram consumidos por $63 \%$ das crianças Waldorf, contra 4,5\% nas escolas controle. Testes cutâneos e exames de sangue mostraram que as crianças Waldorf apresentaram menor prevalência de atopia do que os controles, em média $50 \%$ menos. Este estudo concluiu que a prevalência de atopia foi menor em crianças de famílias antroposóficas suecas do que em crianças de outras famílias e que fatores de estilo de vida associados à Antroposofia podem diminuir o risco de atopia na infância, destacando-se uma dieta 
ISSN 2179-6750

composta por legumes espontaneamente fermentados por lactobacilos e um uso restritivo de antibióticos e antipiréticos. ${ }^{65}$

Estes achados suecos foram confirmados por Flöistrup et al. em 2006 atraves de estudo transversal multicêntrico com 6.630 crianças de 5 a 13 anos (4.606 de escolas Waldorf e 2.024 de escolas de referência) em cinco países europeus. Houve reduções estatisticamente significativas dos riscos de rinoconjuntivite, eczema atópico e sensibilização atópica (IgE alérgeno-específico $\geq 0,35 \mathrm{kU} / \mathrm{L}$ ), com alguma heterogeneidade entre os países. As características do estilo de vida antroposófico mais significativas associadas ao risco reduzido de doença alérgica em crianças foram uso restritivo de antibióticos e antipiréticos. ${ }^{66}$

Considerando que a flora intestinal possui um impacto sobre o desenvolvimento do sistema imunológico, um estudo conduzido por Alm et at. em 2012 avaliou a flora intestinal em lactentes (com menos de 2 anos de idade) comparando 69 crianças com estilo de vida antroposófico (A) com 59 crianças de idade semelhante com estilo de vida tradicional. Foram analisados parâmetros clínicos, resposta a questionários e exame das fezes com quantificação bacteriana, tipagem bacteriana por meio de impressões digitais bioquímicas e pela medição de características associadas à microflora. $\mathrm{O}$ número de unidades formadoras de colônias de fezes foi significativamente maior para enterococos e bactérias lácticas em crianças que nunca haviam sido expostas à antibióticos. O número de enterococos foi significativamente maior em lactentes amamentados e vegetarianos ( $\mathrm{p}$ $<0,01)$. Várias caracteristicas da microflora foram relacionados a características específicas de estilo de vida, e crianças A tinham uma maior proporção de ácido acético e uma menor proporção de ácido propiônico nas fezes em comparação com as crianças controle. A conclusão deste estudo é que fatores do estilo de vida antroposófico influenciaram a composição da flora intestinal nos lactentes e essas diferenças podem contribuir para a menor prevalência de doença atópica previamente observada em crianças de famílias antroposóficas. ${ }^{67}$

Para analisar melhor o estilo de vida antroposófico, o estudo PARSIFAL em 2006 comparou a prevalência de doenças alérgicas entre crianças de áreas agrícolas, crianças de famílias que frequentam a pedagogía antroposófica e crianças como grupo controle, com o objetivo de identificar fatores que possam proteger contra doenças alérgicas. Este estudo coorte incluiu 14.893 crianças, com idade entre 5 e 13 anos, provenientes de famílias de agricultores, famílias de escolas recrutadas de escolas Waldorf e crianças controle na Áustria, Alemanha, Holanda, Suécia e Suíça. Foi concluído um questionário detalhado e mediu-se IgE sérico específico para alergenos. O maior efeito protetor contra todos os resultados estudados, tanto auto-relatados, tais como rinoconjuntivite, eczema atópico e asma e sensibilização ao exame RAST (IgE alérgeno específico 
ISSN 2179-6750

$>0,35 \mathrm{kU} / \mathrm{L}$ ) foi ter crescido em uma fazenda. A prevalência de sintomas alérgicos e sensibilização também foi menor entre as crianças Waldorf em comparação com o grupo controle de forma significativa. A conclusão indicou que o crescimento em uma fazenda, e em menor medida levando um estilo de vida antroposófico pode conferir proteção tanto de sensibilização e doenças alérgicas na infância. ${ }^{68}$

Níveis elevados de cortisol aos 6 meses predizem risco de sensibilização alérgica até 2 anos de idade e, pelo contrario, este risco é minimizado por baixos níveis de cortisol durante a infância. Um estudo de 2015 buscando correlacionar níveis de cortisol e risco de sensibilização a IgE foi conduzido em lactentes comparando estilos de vida dos pais categorizados como antroposófico, parcialmente antroposófico ou não-antroposófico. As amostras de sangue para análise de sensibilização foram obtidas dos pais e das crianças aos 6, 12, 24 e 60 meses de um total de 507 famílias provenientes de Centros de Saúde. As amostras salivares foram coletadas no domicílio aos 6 meses. A sensibilização variou de $2,9 \%$ a $26,0 \%$ no grupo antroposófico, de $8,4 \%$ a $26,8 \%$ no grupo parcialmente antroposófico e de $19,1 \%$ a 44,1\% no grupo não antroposófico. As crianças de famílias antroposóficas apresentaram menores níveis de cortisol na manhã, à tarde e à noite. Os resultados permitiram concluir que crianças de famílias com estilo de vida antroposófico têm menor risco do que os outros grupos comparados de desenvolver sensibilização até 5 anos. ${ }^{69}$

Fagerstedt et al. em 2016 estudando o estilo de vida antroposófico observou um risco reduzido de hipersensibilidade alimentar. Os achados sugerem que a menor prevalência de sensibilização ao alérgeno observada entre crianças de famílias com estilo de vida antroposófico foi amplamente explicada pela baixa incidência de sensibilização alimentar antes de 1 ano de idade. Isto indica que o estilo de vida antroposófico durante o primeiro ano de vida tem um efeito protetor maior na sensibilização a alérgenos. ${ }^{70}$

Entre as abordagens medicamentosas para alergia respiratória, tem sido empregado tradicionalmente o Gencydo®, uma combinação de extrato de limão (Citrus limon) e do marmeleiro (Cydonia oblonga) para o tratamento de pacientes com rinite alérgica ou asma. Um estudo in vitro, conduzido por Gründemann et al., avaliou os efeitos anti-alérgicos desta preparação em linhagens celulares por vários parâmetros biológicos e imunológicos. Este preparado a base de Citrus e Cydonia reduziu a degranulação e a libertação de histamina de células basófilas activadas com IgE e mastócitos e inibiu os aumentos induzidos por IgE na produção de IL-8, TNF- $\alpha$ e GM-CSF em mastócitos. O Gencydo® bloqueou parcialmente a libertação de eotaxina a partir de células epiteliais brônquicas humanas, efeitos comparáveis aos da azelastina e ao corticóide dexametasona. Em conclusão, os resultados proporcionaram uma base racional para o uso tópico de Gencydo® no 
ISSN 2179-6750

tratamento de distúrbios alérgicos através da regulação descendente de mediadores solúveis, os quais são essenciais para o início e manutenção de reacções alérgicas. ${ }^{71}$

\section{Medicina escolar antroposófica}

Dentro da pediatria antroposófica existe uma área específica denominada medicina escolar que tradicionalmente corresponde a participação do médico em uma equipe multidisciplinar em escolas de pedagogia Waldorf. O objetivo destes encontros, geralmente semanais, é a avaliação de crianças saudáveis e doentes, no sentido da percepção precoce e compartilhada de qualquer distúrbio da criança incluindo orientações e encaminhamentos. Neste papel, o pediatra mantém contato com os pais, realiza debates sobre temas de saúde pública como alimentação, drogas, sexualidade, gestação precoce, epidemias e novas vacinas, adota um papel importante na promoção da saúde e prevenção com diagnóstico precoce. ${ }^{40,41}$

\section{Alimentação e Antroposofia}

$\mathrm{Na}$ orientação alimentar infantil a Antroposofia leva em conta alguns conceitos particulares. Um importante princípio é de que o que de fato alimenta a criança é a energia liberada da quebra dos carboidratos, proteínas e lipídeos no processo digestório. Como durante a fotossíntese o carbono do ácido carbônico é unido ao oxigênio e hidrogênio da água na forma de carboidrato (6 $\mathrm{CO}_{2}+6 \mathrm{H}_{2} \mathrm{O}=\mathrm{C}_{6} \mathrm{H}_{12} \mathrm{O}_{6}$ ), durante a hidrólise digestória pela amilase, a energia luminosa é liberada e captada na forma de ATP para assim movimentar todo metabolismo secundário do organismo infantil e permitir a consciência dependente da glicemia. Portanto valoriza-se muito uma alimentaçãoo basicamente vegetariana, orgânica, isenta de conservantes, fresca, não congelada que possa trazer estimulo vegetativo, vitalidade e tranquilidade para a criança. Como as proteínas são substancas nitrogenadas, carregam consigo um estimulo especial para a organização animal da criança, que também são compostos de proteínas, e, portanto, tem um efeito interessante de 'animar' a criança e estimulá-la em seu desenvolvimento neuro-psico-motor.

Durante a fase de lactente, ao redor de 6 meses de idade, coincidentemente com a erupção dos primeiros dentes, a criança necessita realizar uma transição entre o leite materno líquido e doce para os alimentos mais pastosos em direção aos alimentos sólidos e levemente salgados. Como primeiras fontes de carboidratos temos as frutas não ácidas (água de côco, laranja lima, mamão, manga, banana, por exemplo), os cereais (farinha de arroz integral, de milho e de aveia, por exemplo) e os tubérculos (inhame, cará, mandioca, por exemplo). A nitrogenação do carboidrato na natureza é encontrada nas leguminosas que absorvendo nitrogênio do solo por um consórcio com bactérias 
ISSN 2179-6750

criam proteínas vegetais (feijões, lentilhas, ervilhas, grão de bico e soja, de preferência não transgênica). Podemos orientar também o uso de cogumelos frescos e orgânicos como shitake e shimeji, cogumelo paris como fontes de proteínas, seguido dos ovos orgânicos e por fim peixes, frangos e carne bovina orgânicos, privilegiando peixes entre os animais, pela riqueza de ômega 3 , importante para o neurodesenvolvimento. O importante é perceber se a criança necessita e tolera as proteínas, pois devem ser consumidas em quantidade bem menor do que os vegetais e evitadas antes dos 6 meses de vida, exceto em casos de ausência do leite materno e sabendo do risco da sensibilização alergênica.

Um outro aspecto importante é considerar uma fisiologia comparada vegetal e humana, considerando que as raízes (cenoura, beterraba, por exemplo) tem relação e alimentam o SNS (neurológico) da criança, as folhas (verduras como acelga, esfinafre, alface, couve, repolho, por exemplo) possuem função respiratória e alimentam o SR (cardio-respiratório) e os frutos (legumes como abobrinha, abobora, chuchu, ervilhas), flores (couve-flor, brócolis, couve de Bruxelas) e frutas (frutos com frutose) estimulam o metabolismo (sistema digestório e uro-genital). Com base nesta visão analógica, o prato da criança deve conter partes diferentes da planta permitindo uma alimentação mais completa, além das proteínas e gorduras de boa qualidade e quantidade adequadas para o aporte de vitaminas, ferro e ácidos graxos insaturados. Atraves de conceitos bem claros e pautados em bom senso pode-se conduzir uma orientação alimentar bem rica e sem necessidade de modismos excessivamente industrializados. ${ }^{40,41,38}$

\section{Oncologia infantil}

O emprego das PICS associados a terapêutica padrão no modelo da medicina integrativa em crianças oncológicas tem sido bem frequente ao redor do mundo. Segundo a literatura, entre os países de maior emprego deste modelo de oncologia pediatrica integrativa estão em ordem decrescente o Sul da Ásia (84,5\% dos pacientes), Singapura (66\%), os EUA em Washington (63\%) e em Minnesota (59\%), o Canadá $(49 \%)$ e Turquia $(48,9 \%) .{ }^{72-77}$

Embora o uso na Alemanha seja menor do que nestes países (35\%), 27\% destes 35\% pacientes se referem a medicina antroposófica e demonstram maior grau de satisfação na análise comparativa com outras modalodades integrativas neste estudo. O estudo retrospectivo de Längler et al. estudou a prevalência do uso de PICS em oncologia infantil e os fatores relacionados ao seu eu uso entre pelo German Childhood Cancer Registry em 2001. Dos 1.063 questionários avaliados, $35 \%$ dos respondedores usaram as PICS, sendo que os mais utilizados foram a homeopatia, suplementos dietéticos e medicina antroposófica, incluindo a terapia do Viscum. Os fatores socio- 
ISSN 2179-6750

demográficos associados ao uso da PICS foram a maior escolaridade dos pais, maior renda familiar, maior status social e mau prognóstico da doença da criança. As razões mais freqüentemente mencionadas para o uso de PICS foram a estabilização da saúde física, fortaleciemnto do sistema imunológico e melhora da chance de cura. Enquanto as fontes de informação sobre as PICS eram na maioria dos casos não médicas, $71 \%$ dos usuários haviam falado com um médico sobre o seu uso. Os efeitos da PICS percebida pelos pais foram, em sua maior parte, positivos. Oitenta e nove por cento dos usuários relataram que recomendariam estas práticas a outros pais. ${ }^{78}$

Em outro estudo alemão realizado treze anos após com 497 participantes, no sentido de diferenciar o uso de PICS em oncologia pediátrica entre crianças e adolescentes, verificaram que dos 457 entrevistados (92\%), 322 eram crianças (70\%) e 135 adolescentes com mais de 16 anos de idade (30\%). O uso das PICS era de 31\% no momento do diagnóstico e de $41 \%$ como uso prévio ao diagnostico do câncer. As terapias mais prevalentes foram a homeopatia, massagem, medicina antroposófica, acupuntura e flores de Bach. As principais razões para o uso foram as mesmas do estudo anterior além de redução dos efeitos colaterais relacionados à terapia. A maioria dos usuários de PICS (97\%) recomendaria o seu uso e a maioria dos usuários $(78 \%)$ informou um médico sobre o uso. Os efeitos colaterais raramente foram relatados $(5 \%)$ e auto-limitados. ${ }^{79}$

Um estudo de coorte prospectivo sobre massagem rítmica (MR) em crianças conduzido por Wälchli et al. em pacientes não hospitalizados (aproximadamente 20\% com diagnóstico de câncer) em um ambiente clínico, examinou os efeitos da MR em parâmetros clínicos e fisiológicos. Os autores acharam melhoras significativas nos parâmetros clínicos (melhora dos sintomas e qualidade de vida) após um período de tratamento de três meses. A avaliação dos parâmetros fisiológicos mostrou um aumento na temperatura dorsal assim como uma melhor distribuição do calor e atividade autonômica aumentada após a fase de descanso após a massagem como efeitos de curto prazo logo após o tratamento. Em longo prazo houve melhora na qualidade do sono no decorrer do tratamento assim como efeitos positivos na distribuição da temperatura e variabilidade da frequência cardíaca. ${ }^{37}$

Desde 2016 estabeleceu-se uma parceria institucional entre o Instituto de Tratamento de Câncer Infantil do Instituto da Criança do Hospital das Clínicas da Faculdade de Medicina da Universidade de São Paulo (ITACI/ICr/HC/FMUSP) com o Departamento de Oncologia Pediátrica da Faculdade de Medicina do Hospital Universitário da Universidade Charité em Berlin, no sentido de desenvolver um Programa de Pediatria Integrativa e um Centro de Ensino, Pesquisa e Extensão em Praticas Integrativas e Complementares em Saúde Infantil na USP. O programa se iniciou com a Enfermagem Antroposófica e vem se expandindo para toda a área das PICS com uma equipe 
ISSN 2179-6750

multiprofissional para todo Instituto da Criança. ${ }^{80}$

O programa prevê treinamento das enfermeiras em técnicas denominadas Terapias Externas Antroposóficas (TEA) indicadas para melhora do cuidado à criança com câncer e seus familiares e multiplicar este modelo de humanização e excelência técnica para os cuidados em todos níveis de complexidade utilizando este modelo integrativo também em hospitais. Os componentes centrais do cuidado da enfermagem antroposófica são o cuidado do ritmo (respiratório, cardíaco, metabólico, circadiano sono-vigília, semanal, mensal e annual etc.), termoregulação, toque direto incluindo compaixão e atenção empática, com atmosfera calma e segura. ${ }^{81,82}$ As TEA indicados para sintomas comuns em pacientes oncológicos pediátricos são expressas na Tabela 1.

Em estudo de 2016, Schütze et al. compararam o uso de Praticas Integrativas e Complementares (PICS) em cuidados paliativos em crianças com câncer na Alemanha. Numa primeira avaliação de coorte em 2000 o uso de PICS foi de 38\% e em 2006 foi de 49\%. Os tipos mais comuns de PICS utilizados em ambos os grupos foram homeopatia e tratamento com Viscum album. ${ }^{83} \mathrm{O}$ extrato aquoso da planta Viscum album L. (Loranthaceace) é o principal medicamento antroposófico usado de forma coadjuvante e complementar no câncer, geralmente por via subcutânea, mas também endovenosa, intracavitária (pleurodese) e intratumoral. ${ }^{84}$ Este fitofármaco possui uma variedade de substâncias biologicamente ativas como glicoproteínas, viscotoxinas, polissacarídeos, flavonoides, triterpenos e alcalóides. Entre as glicoproteínas, as lectinas I, II e III são bem caracterizadas como responsáveis pela ação citotóxica para células tumorais. $\mathrm{O}$ extrato apresenta efeito imunoestimulante pela ativação de linfocitos com liberação de citosinas, inibição da proliferação celular e indução da apoptose in vitro e in vivo via caspases. Sua ação citotóxica e anti-metastática tem sido demonstrada em diferentes tumores sólidos em estudos clínicos com carcinoma de pâncreas, adenocarcinoma de mama, de estômago, colo-retal, próstata e colo uterino em adultos, além de céluas de leucemia e sarcomas in vitro e in vivo. 
ISSN 2179-6750

Tabela 1. Indicação e modalidade de Terapia Externa Antroposófica em oncologia pediátrica

Indicação

Dificuldade em iniciar o sono

Agitação/inquietação (pós-operatório, por exemplo)
Terapias externas antroposóficas

Deslizamento rítmico de óleos: pés

Deslizamento rítmico de óleos: costas

Escalda pés com oleo óleo de lavanda, limão ou pinho (Picea abies)

Compressa com pomada de Aurum/Lavanda na região precordial

Compressa no epigastrio (Lavanda, Solum oleaginosum, Rosa canina)

Deslizamento rítmico nas mãos (limão)

Enfaixamento abdominal com chá de Camomila

Vômito

Enfaixamento abdominal com pomada de Oxalis

Compressa de Camomila sobre no epigastrio

Náusea

Enfaixamento de Aquilea milefolium em hipocôndrio direito

Deslizamento rítmico de óleos: abdômen (funcho, limão, bálsamo, tomilho)

Constipação

Compressa com pomada de Oxalis em epigastrio

Enfaixamento com óleo de Rosmarinus

Enfaixamento abdominal com chás de Camomila e Aquilea

Gastrite

Deslizamento rítmico com pomada de Cuprum met.

Extremidades frias

Deslizamento rítmico com óleo de Solum

Escalda pés com Salvia off.

Deslizamento rítmico com óleo de Solum

Dor/tensão

Deslizamento rítmico com óleo de Malva

Dor de cabeça

Escalda pés (gengibre, limão)

Humor disfórico

Aplicação externa rítmica com óleo de Solum

Aplicação externa rítmica com óleo de Rosa

Transtorno de ansiedade, ataques de pânico, tratamento paliativo, síndrome de stress pós-traumático

Agitação psico-motora

Deslizamento rítmico com óleo de Rosa

Deslizamento rítmico com óleo de Prunus spinosa

Caquexia

Deslizamento rítmico com óleo de Prunus spinosa

Fonte: Produzido pelo autor (2017). 
ISSN 2179-6750

Sua ação promove aumento de qualidade de vida do paciente oncológico, o que se traduz em redução da fadiga, aumento da disposição medida pelo índice de Karnofsky, recuperação mais rápida da leucopenia induzida pela quimioterapia (por estimulo de GM-CSF), redução dos efeitos adversos à quimioterapia e radioterapia, imunoestimulação (especialmente de linfócitos NK Natural Killer) e melhora no reparo do DNA. O Viscum album aumenta a liberação de betaendorfina endógena, o que traz um efeito analgésico para os pacientes oncológicos. Embora a maioria dos estudos se concentre em pacientes adultos com resultados animadores, a literatura em oncologia infantil ainda é escassa. ${ }^{85-89}$

\section{Conclusão}

A Antroposofia, e em particular a Medicina Antroposófica, aplicadas à Saúde Infantil corresponde a um modelo multimodal e multiprofissional europeu de cuidado integral à saúde que vem sendo implementado no Brasil há mais de cinco décadas. Enquanto na Europa, e especialmente na Alemanha, vem sendo empregada em todos os níveis de complexidade e em hospitais, no Brasil tem sido usada historicamente na atenção primária, em consultórios privados e recentemente em oncologia pediátrica na atenção terciária. As evidências na saúde infantil provem basicamente de estudos internacionais e se concentram nas áreas de imunologia, infectologia, alergia, nutrição, oncologia pediátrica, medicina escolar e estilo de vida. Uma das contribuições importantes de origem brasileira é o Método Padovan de Reorganização Neurofuncional, empregado basicamente por fonoaudiólogos. As evidências mostram que o emprego da Antroposofia como modelo complementar integrativo apresentam ótimo nível de segurança. Uma grande área em particular que a Medicina Antroposófica tem a colaborar na pediatria é na redução do emprego abusivo de antibióticos, anti-inflamatórios não-hormonais e hormonais em infeções respiratórias agudas e alergias respiratórias, com boa taxa de resolução e segurança. Uma outra área muito promissora é a aplicação de técnicas de enfermagem denominadas terapias externas antroposóficas com baixo custo e boa efetividade que podem ser expandidas em todos os níveis de complexidade. A pesquisa no Brasil é muito incipiente nesta área e mais estudos colaborativos serão necessários nos próximos anos para a ampla incorporação destas práticas em saúde pública e na prática clínica pediátrica em geral.

\section{Referências}

1. Boon H, Verhoef M, O’Hara D, Findlay B, Majid N. Integrative healthcare: arriving at a working definition. Altern Ther Health Med. 2004 Sep-Oct;10(5):48-56. 
ISSN 2179-6750

2. Otani MAP, Barros NF. A medicina integrativa e a construção de um novo modelo na saúde. Cien Saude Colet. 2011;16(3):1801-11. http://dx.doi.org/10.1590/S141381232011000300016.

3. Maizes V, Caspi O. The principles and challenges of integrative medicine: more than a combination of traditional and alternative therapies. West J Med. 1999 Sep;171(3):148-9.

4. Ross C, Haussler KK, Kenney JD, Marks D, Bertone JJ, Henneman K, et al. Frontier medicine: the future and integrative medicine. Vet Clin North Am Equine Pract. 2001 Aug;17(2):351-77.

5. EUROCAM. What is CAM? [Internet]. Brussels: EUROCAM; 2015 [citado 2016 nov 10]. Disponível em: http://www.cam-europe.eu/cam-definition.php

6. Zuzak TJ, Zuzak-Siegrist I, Rist L, Staubli G, Simões-Wüst AP. Medicinal systems of complementary and alternative medicine: a cross-sectional survey at a pediatric emergency department. J Altern Complement Med. 2010 Apr;16(4):473-9. http://dx.doi.org/10.1089/acm.2009.0601.

7. World Health Organization. WHO traditional medicine strategy: 2014-2023 [Internet]. Geneva: WHO; 2013 [citado 2016 nov 10]. Disponível em: http://apps.who.int/iris/bitstream/10665/92455/1/9789241506090_eng.pdf

8. Ministério da Saúde (BR). Portaria 1.600 de 17 de julho de 2006. Aprova a constituição do Observatório das Experiências de Medicina Antroposófica no Sistema Único de Saúde (SUS). Brasília, DF: Ministério da Saúde; 2006 [citado 2016 nov 11]. Disponível em: http://www.saude.mg.gov.br/atos_normativos/legislacao-sanitaria/estabelecimentos-desaude/terapias-alternativas/Portaria_1600.pdf

9. Benevides I. Inserção da medicina antroposófica no Sistema Único de Saúde: aspectos históricos, marcos normativos e desafios para sua implementação. Arte Med Ampl. 2012;32(1): 4-11.

10. Luz MT, Afonso VW. A medicina antroposófica como racionalidade médica e prática integral de cuidado à saúde: estudo teórico-analítico e empírico. Juiz de Fora: UFJF; 2014.

11. Längler A, Zuzak TJ. Complementary and alternative medicine in paediatrics in daily practice-a European perspective. Complement Ther Med. 2013 Apr;21(Suppl 1):S26-33. http://dx.doi.org/10.1016/j.ctim.2012.01.005.

12. Plasschaert AIO, Rovers MM, Schilder AGM, Verheij TJM, Hak E. Trends in doctor consultations, antibiotic prescription, and specialist referrals for otitis media in children: 19952003. Pediatrics. 2006 Jun;117(6):1879-86. http://dx.doi.org/10.1542/peds.2005-2470. 
ISSN 2179-6750

13. André M, Vernby A, Odenholt I, Lundborg CS, Axelsson I, Eriksson M, et al. Diagnosisprescribing surveys in 2000, 2002 and 2005 in Swedish general practice: consultations, diagnosis, diagnostics and treatment choices. Scand J Infect Dis. 2008;40(8):648-54. http://dx.doi.org/10.1080/00365540801932439.

14. Jong J, van den Berg PB, de Vries TW, de Jong-van den Berg LTW. Antibiotic drug use of children in the Netherlands from 1999 till 2005. Eur J Clin Pharmacol. 2018 Sep;64(9):9139. http://dx.doi.org/ 10.1007/s00228-008-0479-5.

15. Thompson PL, Gilbert RE, Long PF, Saxena S, Sharland M, Wong IC. Has UK guidance affected general practitioner antibiotic prescribing for otitis media in children?. J Public Health (Oxf). 2008 Dec;30(4):479-86. http://dx.doi.org/10.1093/pubmed/fdn072.

16. Meropol SB, Chen Z, Metlay JP. Reduced antibiotic prescribing for acute respiratory infections in adults and children. Br J Gen Pract. 2009 Oct;59(567):e321-8. http://dx.doi.org/10.3399/bjgp09X472610.

17. Spinks A, Glasziou PP, Del Mar CB. Antibiotics for sore throat. Cochrane Database Syst Rev. 2013 Nov 5;(11):CD000023. http://dx.doi.org/10.1002/14651858.CD000023.pub4.

18. Smith SM, Fahey T, Smucny J, Becker LA. Antibiotics for acute bronchitis. Cochrane Database Syst Rev. 2014 Mar 1;(3):CD000245. http://dx.doi.org/10.1002/14651858.CD000245.pub3.

19. Kenealy T, Arroll B. Antibiotics for the common cold and acute purulent rinitis. Cochrane Database Syst Rev. 2013 Jun 4;(6):CD000247. http://dx.doi.org/10.1002/14651858.CD000247.pub3.

20. Venekamp RP, Sanders S, Glasziou PP, Del Mar CB, Rovers MM. Antibiotics for acute otitis media in children. Cochrane Database Syst Rev. 2016 Jun 12;(6):CD009163. http://dx.doi.org/10.1002/14651858.CD009163.pub3.

21. Rosenfeld RM, Kay D. Natural history of untreated otitis media. Laryngoscope. 2003 Oct;113(10):1645-57. https://doi.org/10.1097/00005537-200310000-00004.

22. Petersen I, Johnson AM, Islam A, Duckworth G, Livermore DM, Hayward AC. Protective effect of antibiotics against serious complications of common respiratory tract infections: retrospective cohort study with the UK General Practice Research Database. BMJ. 2007 Nov;335(7627):982. https://doi.org/10.1136/bmj.39345.405243.BE.

23. Wise R, Hart T, Cars O. Antimicrobial resistance. BMJ. 1998;317(7159):609. https://doi.org/10.1136/bmj.317.7159.609.

24. Penders J, Kummeling I, Thijs C. Infant antibiotic use and wheeze and asthma risk: a 258 
ISSN 2179-6750

systematic review and meta-analysis. Eur Respir J. 2011 Aug;38(2):295-302.

https://doi.org/10.1183/09031936.00105010.

25. Schmitt J, Schmitt NM, Kirch W, Meurer M. Early exposure to antibiotics and infections and the incidence of atopic eczema: a population-based cohort study. Pediatr Allergy Immunol. 2010 Mar;21(2 Pt 1):292-300. https://doi.org/10.1111/j.1399-3038.2009.00901.x.

26. Shaw SY, Blanchard JF, Bernstein CN. Association between the use of antibiotics in the first year of life and pediatric inflammatory bowel disease. Am J Gastroenterol 2010 Dec;105(12):2687-92. https://doi.org/10.1038/ajg.2010.398.

27. European Commission. Communication from the Commission to the European Parliament and the Council: action plan against the rising threats from antimicrobial resistance. European Commission, Brussels: EC; 2011.

28. Mölstad S. Reduction in antibiotic prescribing for respiratory tract infections is needed!. Scand J Prim Health Care. 2003 Dec;21(4):196-8.

29. Spiro DM, Tay KY, Arnold DH, Dziura JD, Baker MD, Shapiro ED. Wait-and-see prescription for the treatment of acute otitis media: a randomized controlled trial. JAMA. 2006 Sep 13;296(10):1235-41. https://doi.org/ 10.1001/jama.296.10.1235.

30. Spurling GK, Del Mar CB, Dooley L, Foxlee R. Delayed antibiotics for respiratory infections. Cochrane Database Syst Ver. 2007 Jul 18;(3):CD004417. https://doi.org/10.1002/14651858.CD004417.pub3. Atualizado em Cochrane Database Syst Rev. 2013.

31. International Federation of Anthropososophical Medicine Associations. Facts and Figures on Anthroposophic Medicine (AM) Worldwide, July 2012. [Dornach]: IVAA; 2012 [citado 2016 nov 10]. Disponível em: http://www.ivaa.info/fileadmin/editor/file/Facts_and_Figures_AM_WorldwideJuly2012_Fin al_Public_Light.pdf

32. Agência Nacional de Vigilância Sanitária (BR). Resolução no. 26, de 30 de março de 2007. Dispõe sobre o registro de medicamentos dinamizados industrializados homeopáticos, antroposóficos e anti-homotóxicos. Diário Oficial da União: 2007 Abr 2; Seção 1:57-62.

33. Ambiente virtual de Aprendizagem do SUS. Módulo Introdutório em Práticas Integrativas e Complementares: Antroposofia Aplicada à Saúde. Comunidade de Práticas, Instituto Communitas para o Desenvolvimento Humano e Tecnológico, Ministério da Saúde, 2016. Disponível em: https://avasus.ufrn.br/local/avasplugin/cursos/cursos.php?search=antroposofia 
ISSN 2179-6750

34. Lievegoed B. Fases da vida: crises e desenvolvimento da individualidade. São Paulo: Antroposófica; 1984.

35. Burkhard G. Bases Antroposóficas da Metodologia Biográfica. São Paulo: Antroposófica; 2002.

36. Hauschka M. Massagem rítmica: fundamentos antroposóficos. São Paulo: Antroposófica; 1985.

37. Wälchli C, Saltzwedel G, Krüerke D, Kaufmann C, Schnorr B, Rist L, Eberhard J, et al. Physiologic effects of rhythmical massage: a prospective exploratory cohort study. J Altern Complement Med. 2014 Jun;20(6):507-15. https://doi.org/10.1089/acm.2012.0833. Epub 2013 May 23.

38. Moraes WA, Salutogênese e autocultivo: uma abordagem interdisciplinar. São Paulo: Antroposófica; 2015.

39. Kienle GS, Albonico U, Baars E, Hamre HJ, Zimmermann P, Kiene H. Medicina antroposófica: um sistema de medicina integrativa originado na Europa. Arte Med Ampl. 2015;35(1):7-19.

40. Wolff O, Husemann, F. A imagem do homem como base da arte médica: esboço de uma medicina orientada pela ciência espiritual: patologia e terapêutica. Vol. I. São Paulo: Resenha Universitária; 1978.

41. Wolff O. A imagem do homem como base da arte médica: esboço de uma medicina orientada pela ciência espiritual: patologia e terapêutica vol II. São Paulo: ABMA; 1984.

42. Vieira PMO. Saúde da família e medicina antroposófica: relato de experiência. Arte Med Ampl. 2004; 24(3-4):20-9.

43. Bott V. Medicina antroposófica: uma ampliação na arte de curar: plantas e metais. Vol. II. São Paulo: Associação Beneficiente Tobias; 1982.

44. Steiner R, Wegman I. Elementos fundamentais para uma ampliação da Arte de Curar: segundo os conhecimentos da ciência espiritual. 3a ed. São Paulo: Antroposófica; 2007.

45. Gardin NE. Medicamentos dinamizados injetáveis: justificativas científicas. Arte Med Ampl. 2008;28(3-):20-4.

46. Gardin NE, Schleier R. Medicamentos antroposóficos: vademecum. São Paulo: João de Barro; 2009.

47. Jeschke E, Ostermann T, Tabali M, Kröz M, Bockelbrink A, Witt CM, et al. Anthroposophic medicine in pediatric primary care: a prospective, multicenter observational study on prescribing patterns. Altern Ther Health Med. 2011 Mar-Apr;17(2):18-28. 
ISSN 2179-6750

48. Padovan BA. Neurofunctional reorganization in myo-osteo-dentofacial disorders: complementary roles of orthodontics, speech and myofunctional therapy. Int J Orofacial Myology. 1995 Nov;21:33-40.

49. Ghelman R, Nakamura MU, Hosomi JK, Perlatto R, Orgolini V, Aldred A, et al. Efficacy of a multimodal non-invasive pain management with anthroposophic therapies and transdermal gel in Post-Polio Syndrome (PPS): prospective, randomized, double-blind placebo controlled clinical trial. Poster presented at: International Congress of Integrative Health and Medicine; 2016 Jun 3-6; Stuttgart, Germany.

50. Harman WW. Mind and healing-removing obstacles which have inhibited enquiry. S Afr Med J. 1993;83(5):312-3.

51. Schlitz M, Taylor E, Lewis N. Toward a noetic model of medicine. Noetic Sci Ver. 1998;(47):44-52.

52. Coelho Júnior, AG, Mahfoud M. As Dimensões religiosa e espiritual da experiência humana: distinções e inter-relações na obra de Viktor Frankl. Psicol USP. 2001;12(2):95103. https://doi.org/10.1590/S0103-65642001000200006.

53. Ghelman R, Hosomi JK, Yaari M, Castro AV, Pravatto Junior M, Costa LAN, et al. Ficha clínica antroposófica do núcleo de medicina antroposófica da Universidade Federal de São Paulo. Arte Med Ampl. 2012 jan-mar;32(1):12-21.

54. Gardin NE. Quadrimembração: as quatro organizações que constituem o ser humano de acordo com a antroposofia. Arte Med Ampl. 2015 jun-set;35(3):101-9.

55. Kröninger-Jungaberle H, Grevenstein D. Development of salutogenetic factors in mental health - Antonovsky's sense of coherence and Bandura's self-efficacy related to Derogatis' symptom check list (SCL-90-R). Health Qual Life Outcomes. 2013 May 8;11:80. https://doi.org/ 10.1186/1477-7525-11-80.

56. Groom A, Elliott HR, Embleton ND, Relton CL. Epigenetics and child health: basic principles. Arch Dis Child. 2011 Sep;96(9):863-9. https://doi.org/10.1136/adc.2009.165712.

57. Ghelman R. O desenvolvimento da resiliência durante a infância [Internet]. São Paulo: Aliança pela Infância; 2016 [acesso em 6 jun 2018]. Disponível em: http://aliancapelainfancia.org.br/inspiracoes/o-desenvolvimento-da-resiliencia-durante-ainfancia/

58. Kienle GS, Kiene H, Albonico HU. Anthroposophic medicine - Effectiveness, utility, costs and safety. Stuttgart: Schattauer; 2006. 
ISSN 2179-6750

59. Hamre HJ, Fischer M, Heger M, Riley D, Haidvogl M, Baars E, et al. Anthroposophic vc. Conventional therapy of acute respiratory and ear infections: a prospective outcomes study. Wien Klin Wochenschr. 2005 Ap;117(7-8):256-68.

60. Hamre HJ, Glockmann A, Schwarz R, Riley DS, Baars EW, Kiene H, et al. Antibiotic use in children with acute respiratory or ear infections: prospective observational comparison of anthroposophic and conventional treatment under routine primary care conditions. Evid Based Complement Alternat Med. 2014;2014:243801. https://doi.org/10.1155/2014/243801.

61. Chernyshov VP, Heusser P, Omelchenko LI, Chernyshova LI, Vodyanik MA, Vykhovanets $\mathrm{EV}$, et al. Immunomodulatory and clinical effects of Viscum album (Iscador M and Iscador P) in children with recurrent respiratory infections as a result of the Chernobyl nuclear accident. Am J Ther. 2000 May;7(3):195-203.

62. Stoss M, Michels C, Peter E, Beutke R, Gorter RW. Prospective cohort trial of Euphrasia single-dose eye drops in conjunctivitis. J Altern Complement Med. 2000 Dec;6(6):499_ 508. https://doi.org/10.1089/acm.2000.6.499.

63. Andriashvili L, Karseladze R, Ulrich B. Anthroposophic aspects of bronchial asthma treatment in childhood. Georgian Med News. 2007 Mar;(144):43-8. [German].

64. Hamre HJ, Witt CM, Kienle GS, Schnürer C, Glockmann A, Ziegler R, et al. Anthroposophic therapy for asthma: A two-year prospective cohort study in routine outpatient settings. J Asthma Allergy. 2009 Nov 24;2:111-28.

65. Alm JS, Swartz J, Lilja G, Scheynius A, Pershagen G. Atopy in children of families with an anthroposophic lifestyle. Lancet. 1999 May 1;353(9163):1485-8. https://doi.org/10.1016/S0140-6736(98)09344-1.

66. Flöistrup H1, Swartz J, Bergström A, Alm JS, Scheynius A, van Hage M, et al. Allergic disease and sensitization in Steiner school children. J Allergy Clin Immunol. 2006 Jan;117(1):59-66. https://doi.org/10.1016/j.jaci.2005.09.039.

67. Alm JS, Swartz J, Björkstén B, Engstrand L, Engström J, Kühn I, et al. An anthroposophic lifestyle and intestinal microflora in infancy. Pediatr Allergy Immunol. 2002 Dec;13(6):402-11. https://doi.org/10.1034/j.1399-3038.2002.01062.x.

68. Alfvén T, Braun-Fahrländer C, Brunekreef B, von Mutius E, Riedler J, Scheynius A, et al. Allergic diseases and atopic sensitization in children related to farming and anthroposophic lifestyle: the PARSIFAL study. Allergy. 2006 Apr;61(4):414-21. https://doi.org/10.1111/j.1398-9995.2005.00939.x. 
ISSN 2179-6750

69. Swartz J, Lindblad F, Arinell H, Theorell T, Alm J. Anthroposophic lifestyle and salivary cortisol are associated with a lower risk of sensitization during childhood. Pediatr Allergy Immunol. 2015 Mar;26(2):153-60. https://doi.org/10.1111/pai.12342.

70. Fagerstedt S, Hesla HM, Ekhager E, Rosenlund H, Mie A, Benson L, Scheynius A, Alm J. Anthroposophic lifestyle is associated with a lower incidence of food allergen sensitization in early childhood. J Allergy Clin Immunol. 2016 Apr;137(4):1253-6. https://doi.org/10.1016/j.jaci.2015.11.009.

71. Gründemann C, Papagiannopoulos M, Lamy E, Mersch-Sundermann V, Huber R. Immunomodulatory properties of a lemon-quince preparation (Gencydo ${ }^{\circ}$ ) as an indicator of anti-allergic potency. Phytomedicine. 2011 Jun 15;18(8-9):760-8. https://doi.org/10.1016/j.phymed.2010.11.016.

72. Gözüm S, Arikan D, Büyükavci M. Complementary and alternative medicine use in pediatric oncology patients in eastern Turkey. Cancer Nurs. 2007 Jan-Feb;30(1):38-44.

73. Martel D, Bussières JF, Théorêt Y, Lebel D, Kish S, Moghrabi A, et al. Use of alternative and complementary therapies in children with cancer. Pediatr Blood Cancer. 2005 Jun 15;44(7):660-8. https://doi.org/10.1002/pbc.20205.

74. Post-White J1, Fitzgerald M, Hageness S, Sencer SF. Complementary and alternative medicine use in children with cancer and general and specialty pediatrics. J Pediatr Oncol Nurs. 2009 Jan-Feb;26(1):7-15. https://doi.org/10.1177/1043454208323914.

75. Neuhouser ML, Patterson RE, Schwartz SM, Hedderson MM, Bowen DJ, Standish LJ. Use of alternative medicine by children with cancer in Washington state. Prev Med. 2001 Nov;33(5):347-54. https://doi.org/10.1006/pmed.2001.0911.

76. Lim J, Wong M, Chan MY, Tan AM, Rajalingam V, Lim LP, et al. Use of complementary and alternative medicine in paediatric oncology patients in Singapore. Ann Acad Med Singapore. 2006 Nov;35(11):753-8.

77. Hamidah A, Rustam ZA, Tamil AM, Zarina LA, Zulkifli ZS, Jamal R. Prevalence and parental perceptions of complementary and alternative medicine use by children with cancer in a multi-ethnic Southeast Asian population. Pediatr Blood Cancer. 2009 Jan;52(1):70-4. https://doi.org/10.1002/pbc.21798.

78. Laengler A, Spix C, Seifert G, Gottschling S, Graf N, Kaatsch P. Complementary and alternative treatment methods in children with cancer: A population-based retrospective survey on the prevalence of use in Germany. Eur J Cancer. 2008 Oct;44(15):2233-40. https://doi.org/10.1016/j.ejca.2008.07.020. 
ISSN 2179-6750

79. Gottschling S, Meyer S, Längler A, Scharifi G, Ebinger F, Gronwald B. Differences in use of complementary and alternative medicine between children and adolescents with cancer in Germany: a population based survey. Pediatr Blood Cancer. 2014 Mar;61(3):488-92. https://doi.org/10.1002/pbc.24769.

80. Ghelman R, Taminato M, Odone Filho V, Holmberg C, Längler A. Integrative medicine in nursing care development of an anthroposophical nursing and supportive therapy program for the pediatric unit: integrative care for children with câncer, the therapeutic potential of anthroposophic nursing. Poster presented at: International Congress of Integrative Health and Medicine; 2016 September12-16; Rosenfeld, Germany.

81. Ghelman R. A dor e seu significado no contexto da medicina antroposófica. In: Pimenta CAM, Kurita GP, Galvão ACR, Corrêa CF. Simbidor: arquivos do $8^{\circ}$ Simpósio Brasileiro e Encontro Internacional sobre Dor. São Paulo: Office Editora; 2007.

82. Molassiotis A, Cubbin D.'Thinking outside the box': complementary and alternative therapies use in paediatric oncology patients. Eur J Oncol Nurs. 2004 Mar;8(1):50-60. https://doi.org/10.1016/S1462-3889(03)00054-1.

83. Schütze T, Längler A, Zuzak TJ, Schmidt P, Zernikow B. Use of complementary and alternative medicine by pediatric oncology patients during palliative care. Support Care Cancer. 2016 Jul;24(7):2869-75. https://doi.org/10.1007/s00520-016-3097-2.

84. Kienle GS, Kiene H. Influence of Viscum album L. (European mistletoe) extracts on quality of life in cancer patients: a systematic review of controlled clinical studies. Integr Cancer Ther. 2010 Jun;9(2)142-57. https://doi.org/10.1177/1534735410369673.

85. Schad F, Atxner J, Buchwald D, Happe A, Popp S, Kroz M, et al. Intratumoral Mistletoe (Viscum album L) therapy in patients with unresectable pancreas carcinoma: a retrospective analysis. Integr Cancer Ther. 2014 Jul;13(4):332-40. https://doi.org/10.1177/1534735413513637. Epub 2013 Dec 19.

86. Seifert G, Jesse P, Laengler A, Reindl T, Luth M, Lobitz S. Molecular mechanisms of mistletoe plant extract-induced apoptosis in acute lymphoblastic leukemia in vivo and in vitro. Cancer Lett. 2008 Jun 18;264(2):218-28.

https://doi.org/10.1016/j.canlet.2008.01.036.

87. Orhan DD, Kupeli E, Yesilada E, Ergun F. Anti-inflammatory and antinociceptive activity of flavonoids isolated from Viscum album ssp. album. Z Naturforsch C. 2006 Jan-Feb;61(1-2):26-30.

88. Tabiasco J, Pont F, Fournie JJ, Vercellone A. Mistletoe viscotoxins increase natural 264 
ISSN 2179-6750

killer cell- mediated cytotoxicity. Eur J Biochem. 2002 May;269(10):2591-600.

https://doi.org/10.1046/j.1432-1033.2002.02932.x.

89. Cho HJ, Na KJ, Kim DW, Choi YE, Ma JS, Jeong IS. Chemical pleurodesis using a Viscum album extract in infants with congenital chylothorax. Eur J Pediatr. 2014 Jun;173(6):823- 6. https://doi.org/10.1007/s00431-014-2283-9. 